\title{
Predicting Recessions with Factor Linear Dynamic Harmonic Regressions
}

\author{
MARCOS BUJOSA ${ }^{1 *}$ ANTONIO GARCÍA-FERRER ${ }^{2}$ AND ARÁNZAZU DE JUAN ${ }^{2}$ \\ 1 Departamento de Fundamentos del Análisis Económico II, Universidad Complutense de Madrid, \\ Spain \\ 2 Departamento de Análisis Económico: Economía cuantitativa, Universidad Autónoma de Madrid, \\ Spain
}

\begin{abstract}
We propose a new framework for building composite leading indicators for the Spanish economy using monthly targeted predictors and small-scale dynamic factor models. Our leading indicator index, based on the low-frequency components of four monthly economic variables, is able to predict the onset of the Spanish recessions as well as the gross domestic product (GDP) growth cycles and classical industrial production cycles, both historically and in real time. Also, our leading indicator provides substantial aid in forecasting annual and quarterly GDP growth rates. Using only real data available at the beginning of each forecast period, our indicator one-step-ahead forecasts shows substantial improvements over other alternatives. Copyright () 2013 John Wiley \& Sons, Ltd.
\end{abstract}

KEY WORDS forecasting; linear dynamic harmonic regression; leading indicator; factor analysis; business cycles; Spanish economy

\section{INTRODUCTION}

Historically, time series forecasts of economic variables have used only a handful of predictor variables, while forecasts based on a large number of predictors have been the province of large structural or vector autoregressive (VAR) models (Lütkepohl, 2006). The past decade, however, has seen some progress in the development of time series forecasting methods that exploit many predictors, switching the challenge of turning dimensionality from a curse into a blessing. Lately, the method of 'diffusion index forecasts' (Stock and Watson, 2002) and other variants of factor models have been able to incorporate information in a large number of predictors into the forecasts in a simple and parsimonious way. However, this does not preclude refinements to this methodology. As a matter of fact, a practical question in this approach is how much data are really needed? Directly linked to the previous question is how to find the best way to extract a subset of variables from a larger data set and, how to use it for real-time forecasting.

In several papers (García Ferrer and Poncela, 2002; Boivin and Ng, 2006; Poncela and García Ferrer, 2010; among others) it was found that expanding the sample size simply by adding data that bear little information about the factor components does not necessarily improve forecasts and, when the data are too noisy, we can be better off by throwing away some data even though they are available. Independently of the type of factor model used, we need to consider the properties of the idiosyncratic errors when building the factor components. For instance, Peña and Poncela (2004) find that factor model forecasts heavily depend on the variance ratio of the common and specific parts. When facing volatile variables, forecasts deteriorate if the associated variance of the common component is not high enough in comparison to the variance of the idiosyncratic component. In this regard, it might be preferable (in terms of the forecasts' root mean square errors (RMSEs)) to obtain slightly biased forecasts but showing a lower volatility behaviour.

One strand of growing interest within the multivariate literature consists in examining how the size and composition of the dataset affect the forecasting performance. Bai and $\mathrm{Ng}$ (2008), for instance, use soft and hard thresholding algorithms (Efron et al., 2004) in order to take into account the relationship between the whole dataset and the variable of interest, and principal components are later estimated from a reduced set of variances. de Mol et al. (2008) use an alternative Bayesian double exponential regression selection procedure that imposes limits on the length of the projection parameters through a prior that favours either large or zero coefficients. Also, Chun and Kekes (2010) use sparse partial least squares (PLS), which imposes additional constraints in the PLS method that operates on the direction vectors and leads to sparse linear combinations of the original predictors. In general, the empirical evidence pointed out that the number as well as the quality of the variables

\footnotetext{
* Correspondence to: Marcos Bujosa, Departamento de Fundamentos del Análisis Económico II, Universidad Complutense de Madrid, Somosaguas, 28223 Madrid, Spain.

E-mail: marcos.bujosa@ccee.ucm.es
} 
included in the dataset are relevant for the factor estimation process and the posterior forecasting performance (Eickmeier and $\mathrm{Ng}, 2011$ ).

When dating and predicting business cycle recessions, however, many have used variants of the Markov switching (MS) approach started with Hamilton (1989), which has since been adopted in hundreds of papers. ${ }^{1}$ The two-step procedure of Diebold and Rudebusch (1996) represents one of the earliest attempts to combine factor Models (FM) and Markov switching specifications. Basically, they first extract the common factor and then apply MS to the linear common factor. Besides their complementarity in capturing the fundamental features of business cycles, this combination can also be given a sound justification from an economic theory point of view. Later, Kim and Nelson (1998) proposed a Bayesian approach making Gibb sampling operational for the state-space model with MS and constructed an experimental index of coincident indicators that encompasses both co-movements among economic variables and nonlinearities in the evolution of the business cycle. Many empirical results, though, convey an indisputable message: relationships between variables as well as dynamics evolve over time or shift abruptly. As a consequence, the value of leading indicators of output growth (particularly in the USA) has recently been called into question given the relatively modest improvements that arise from employing combinations of indicators. ${ }^{2}$ Recently, leading indicators have been given a new lease of life in Clements and Galvao $(2008,2009)$ by exploiting the fact that some leading indicators are available at a monthly frequency and using this monthly information directly. They use the MIDAS (MIxed Data Sample) approach of Ghysels et al. (2007) and obtain much larger predictive gains, particularly at shorter horizons.

Our goal in this paper is to obtain a composite leading indicator (CLI) for the Spanish economy using monthly targeted predictors and dynamic factor models, and show how this CLI is able to anticipate the onset of the Spanish recessions. In summary, our main findings are as follows:

1. Contrary to popular wisdom, some signals of recession were evident in the economy before the bursting of the financial bubble in August 2007. For the Spanish case, this announcement was generalized across many economic sectors.

2. Our CLI indicator based upon four cycle drivers, namely housing starts, cement consumption, car registrations and commercial vehicle registrations, provides a similar message regarding recession announcement.

3. When using the whole sample period 1978:M1-2009:M12 our CLI systematically precedes the peaks and troughs of both the gross domestic product (GDP) growth cycles as well as the industrial production classical cycles with leads between one to five quarters.

4. The use of the CLI also provides substantial aid in forecasting annual and quarterly GDP growth rates during the 2008-2009 recession.

5. Using only real data available at the beginning of each forecast period our CLI one-step forecasts shows sizable improvements over other alternatives.

The plan of the rest of our paper is as follows. Section 2 describes the methodology. Section 2.1 describes the linear dynamic harmonic regression (LDHR) model of Bujosa et al. (2007) to obtain the estimated trends of the individual predictors, and Section 2.2 outlines how they can be adapted in the dynamic factor model (DFM) for non-stationary time series developed by Peña and Poncela (2006). Section 3 begins by briefly describing the larger monthly dataset and dating recession dates of these monthly variables, according to the definitions proposed in García-Ferrer and Bujosa-Brun (2000). Section 3.3 describes the construction of our CLI and discusses the estimation results. Section 4.1 presents the in-sample forecasting results of both classical business cycles and deviation or growth cycles, and Section 4.2 presents the out-of-sample forecasting performance. Since monthly data are not available for GDP, we will be using the Industrial Production Index (IPI) as our target variable. Although industrial activity accounts only for a relatively small share of total value added in Spain, its high cyclicality and strong co-movement with GDP make it a good candidate for a more timely cycle indicator. When information is transformed to quarterly and annual data, we evaluate our CLI forecasting performance of the Spanish GDP growth during the 2008-2009 recession. Section 5 offers some concluding remarks.

\section{METHODOLOGY}

\section{The linear dynamic harmonic regression}

Among the alternative unobserved component formulations within the stochastic state-space setting, the dynamic harmonic regression (DHR) model, developed by Young et al. (1999), has proven to be particularly useful for adaptive seasonal adjustment, signal extraction, forecasting and backcasting of time series. This model belongs to

\footnotetext{
${ }^{1}$ See Marcellino (2006) for a comprehensive review of the literature. Some applications can be seen in Chauvet and Piger (2005), among others.

${ }^{2}$ As an example, in Stock and Watson (2003) the combined forecasts of individual indicator model forecasts is only around 5\% better than those obtained with simple AR models.
} 
the unobserved component (UC) models class and is formulated within the state-space framework. The model is based on a spectral approach under the hypothesis that the observed time series can be decomposed into several DHR components whose variances are concentrated around certain frequencies. This hypothesis is appropriate if the observed time series has well-defined spectral peaks, which implies that its variance is distributed around narrow frequency bands.

Here we will be using the linear dynamic harmonic regression (LDHR) version developed by Bujosa et al. (2007). The LDHR is an extension of Young's estimation procedure by linear methods. This extension also provides an automatic identification of the complete DHR model. The LDHR algorithm exploits the autoregressive moving average (ARMA) representation of DHR components in order to (i) identify the spectral peaks, (ii) assign a DHR component to each spectral peak, and (iii) optimize the hyperparameters that control the spectral fit of each component to its corresponding spectral peak. The final estimation of the DHR components is obtained using the Kalman filter (KF) and fixed interval smoothing (FIS) algorithms.

In the univariate case, the DHR model can be written as a special case of the univariate UC model, which has the general form

$$
y_{t}=T_{t}+S_{t}+e_{t} ; \quad t=0,1,2, \ldots
$$

where $y_{t}$ is the observed time series, $T_{t}$ is the trend or low-frequency component, $S_{t}$ is the seasonal component, and $e_{t}$ is an irregular component normally distributed with zero mean value and variance $\sigma_{e}^{2}$. These types of models have been extensively studied in the literature (see, for instance, Kitagawa, 1981; Harvey, 1989; West and Harrison, 1997).

Equation (1) is appropriate for dealing with economic data exhibiting pronounced trend and seasonality, as is the case with the monthly variables used in this paper. When set in state-space form, each component is modelled in a manner which allows $y_{t}$ to be represented as a set of discrete-time equations which are the basis for recursive statespace estimation and forecasting. In the DHR model $T_{t}$ and $S_{t}$ consist of a number of DHR components, $s_{t}^{p_{j}}$, with the general form $s_{t}^{p_{j}}=a_{j t} \cos \left(\omega_{j} t\right)+b_{j t} \sin \left(\omega_{j} t\right)$, where $p_{j}$ and $\omega_{j}=2 \pi / p_{j}$ are the period and the frequency associated with each $j$ th DHR component respectively. $T_{t}$ is the zero frequency term $\left(T_{t} \equiv s_{t}^{\infty}=a_{0 t}\right)$, while the seasonal component is $S_{t}=\sum_{j=1}^{R} s_{t}^{p_{j}}$, being $j=1, \ldots, R$ the seasonal frequency and its harmonics. Hence the complete DHR model is

$$
y_{t}=\sum_{j=0}^{R} s_{t}^{p_{j}}+e_{t}=\sum_{j=0}^{R}\left\{a_{j t} \cos \left(\omega_{j} t\right)+b_{j t} \sin \left(\omega_{j t}\right)\right\}+e_{t}
$$

The oscillations of each DHR component, $s_{t}^{p_{j}}$, are modulated by $\left\{a_{j t}\right\}$ and $\left\{b_{j t}\right\}$ which are $\operatorname{AR}(1)$ or $\operatorname{AR}(2)$ stochastic processes with at least one unit root:

$$
\left.\begin{array}{l}
\left(1-\alpha_{j} B\right)\left(1-\beta_{j} B\right) a_{j_{t}}=\xi_{j_{t-1}} \\
\left(1-\alpha_{j} B\right)\left(1-\beta_{j} B\right) b_{j_{t}}=\xi_{j_{t-1}}
\end{array}\right\} 0 \leq \alpha_{j}, \beta_{j} \leq 1,\left\{\xi_{j}\right\} \sim \text { w.n. } N\left(0, \sigma_{j}^{2}\right)
$$

therefore, non-stationarity is allowed in the various components: random walk (RW; $\alpha=1, \beta=0$ ); smooth-random walk (SRW; $0<\alpha<1, \beta=1$ ) and integrated random-walk (IRW; $\alpha=\beta=1$ ). This DHR model can be considered a straightforward extension of the classical harmonic regression model, in which the gain and phase of the harmonic components can vary as a result of estimated temporal changes in the parameters $a_{j_{t}}$ and $b_{j t} .{ }^{3}$

The variance of the innovations of the $\left\{a_{j t}\right\}$ and $\left\{b_{j t}\right\}$ AR stochastic processes $\left(\sigma_{0}^{2}, \sigma_{1}^{2}, \ldots, \sigma_{R}^{2}\right)$ and the variance $\sigma_{e}^{2}$ of the irregular component are the unknown hyperparameters of the model. ${ }^{4}$ The method for optimizing the hyperparameters of the model (i.e. the variances $\sigma_{d h r}^{2}=\left[\sigma_{0}^{2}, \sigma_{1}^{2}, \ldots, \sigma_{R}^{2}\right]^{\prime}$ of the processes $\xi_{j}, j=0 \ldots, R$, and the variance $\sigma_{e}^{2}$ of the irregular component) was formulated by Young et al. (1999) in the frequency domain, and is based upon expressions for the pseudo-spectrum of the full DHR model:

$$
f_{\mathrm{dhr}}\left(\omega, \sigma^{2}\right)=\sum_{j=0}^{R} \sigma_{j}^{2} S_{j}(\omega)+\sigma_{e}^{2} ; \quad \sigma^{2}=\left[\sigma_{\mathrm{dhr}}^{2}, \sigma_{e}^{2}\right]^{\prime}
$$

\footnotetext{
${ }^{3}$ The main difference between the DHR model and related techniques, such as Harvey's structural model (Harvey, 1989), lies in the formulation of the UC model for the periodic components and the method of optimizing the hyperparameters.

${ }^{4}$ Each $\sigma_{j}^{2}$ is common in the innovations of $\left\{a_{j t}\right\}$ and $\left\{b_{j t}\right\}$.
} 
where $\sigma_{j}^{2} S_{j}(\omega)$ are the pseudo-spectra of the DHR components $s^{p_{j}}$, and $\sigma_{e}^{2}$ is the variance of the irregular component. In the optimization processes the vector $\sigma^{2}$ that minimizes (3) is computed. ${ }^{5}$

$$
\min _{\left[\boldsymbol{\sigma}^{2}\right] \in \mathbb{R}^{R+1}}\left\|f_{y}(\omega)-f_{\mathrm{dhr}}\left(\omega, \boldsymbol{\sigma}^{2}\right)\right\|
$$

where $f_{y}(\omega)$ is the spectrum of the observed time series. The DHR components follow non-stationary ARMA processes (see Bujosa et al., 2007); therefore, in order to find an ordinary least squares (OLS) solution of equation (3) it is needed to eliminate the unit modulus AR roots of $f_{\mathrm{dhr}}\left(\omega, \sigma^{2}\right)$. The DHR components $s_{t}^{p_{j}}$ are stochastic processes of the form (see Bujosa et al., 2007)

$$
\varphi_{j}(B) s_{t}^{p_{j}}=\theta_{j}(B) \xi_{j_{t-1}}, \quad\left\{\xi_{j_{t} t}\right\} \sim \text { w.n. } \quad N\left(0, \sigma_{\xi_{j t}}^{2}\right)
$$

and the pseudo-spectrum ${ }^{6}$ of the complete DHR model is

$$
f_{\mathrm{dhr}}\left(\omega, \boldsymbol{\sigma}^{2}\right)=\sum_{j=1}^{R} \sigma_{j}^{2} \frac{\theta_{j}\left(e^{-i \omega}\right) \theta_{j}\left(e^{i \omega}\right)}{\varphi_{j}\left(e^{-i \omega}\right) \varphi_{j}\left(e^{i \omega}\right)}+\sigma_{e}^{2}
$$

If equation (3) is multiplied by the function $\Psi(\omega)=\Phi\left(e^{-i \omega}\right) \Phi\left(e^{i \omega}\right)$, where $\Phi(B)$ is the minimum-order polynomial with all unit modulus AR roots of the complete DHR model, the algorithm minimizes

$$
\min _{\sigma^{2} \in \mathbb{R}^{R+2}}\left\|\Psi(\omega) \cdot f_{y}(\omega)-\Psi(\omega) \cdot f_{\mathrm{dhr}}\left(\omega, \sigma^{2}\right)\right\|
$$

Finally, $f_{y}(\omega)$ can be substituted in (4) by the estimated periodogram $\widehat{I}(\omega)$ of a pre-whitened series by an AR polynomial $\widehat{\phi_{y}}(B)$ fitted to the series. The size, shape and location of the spectral peaks (the roots of $\widehat{\phi_{y}}(B)$ ) are used to identify the models of each of the DHR components $s^{p_{j}}$; therefore all unit modulus AR roots in $\Psi(\omega)$ are the unit roots in $\widehat{\phi_{y}}(B)$. Hence, because in (4) all the unit modulus AR roots cancel out, the minimization problem (3) can be solved by OLS.

The noise variance ratios $\left(\mathrm{NVR}_{j}=\sigma_{j}^{2} / \sigma_{e}^{2}\right)$ work as smoothing parameters; the smaller the $\mathrm{NVR}_{0}$, the closer to a linear deterministic trend is the estimated trend. In the limit, when $\mathrm{NVR}_{0}=0$ the estimated trend is linear. In the case of seasonal components, the smaller the $\mathrm{NVR}_{j}$, the smoother are the changes in the amplitude of the oscillations of the $j$ th DHR component $s_{t}^{p_{j}}$ (see Young et al., 1999). Our preference for the DHR is due to the advantages of IRW and SRW trend models over other procedures when dealing with monthly series. Although most of the alternatives may track the long-term behaviour in any time series equally well, when we look at their associated first difference transformations the picture changes dramatically. In some cases, estimated trends actually contain some higher-frequency components related to the annual cycle, which are then amplified by the differencing operation. ${ }^{7}$

\section{Dynamic factor model}

Let $\underline{y}_{t}$ be a $m$-dimensional vector of the $m$ time series (the estimated DHR trends). Following Peña and Poncela $(200 \overline{6})$, we assume that this vector can be written as a linear combination of $r<m$ common factors plus noise:

$$
\underline{y}_{t}=\mathbf{P} \underline{f}_{t}+\underline{e}_{t}
$$

where $\underline{f}_{t}$ is the $r$-dimensional vector of common unobserved factors and $\underset{[m \times r]}{\mathbf{P}}$ is a factor loading matrix. We assume all the common dynamic structure in the trends comes through the common factors $\underline{f}_{t}$. We suppose that the vector of common factors follows a vector autoregressive moving average, VARMA $(p, q)$ model:

$$
\boldsymbol{\Phi}_{(B)} \underline{\boldsymbol{f}}_{t}=\boldsymbol{\Theta}(B) \underline{\boldsymbol{a}}_{t}
$$

where $\boldsymbol{\Phi}(B)$ and $\boldsymbol{\Theta}(B)$ are polynomials of $r \times r$ matrices, the roots of the determinant equation $|\boldsymbol{\Phi}(B)|=0$ can be on or outside the unit circle, and $\underline{\boldsymbol{a}}_{t}$ is normally distributed, with zero mean and serially uncorrelated with a full rank

\footnotetext{
${ }^{5}$ In the original work Young et al. (1999) modify the problem using the residual variance $\widehat{\sigma}^{2}$ from the fitted AR model, as estimation of $\sigma_{e}^{2}$, and then dividing by $\widehat{\sigma}^{2}$, so they seek the vector NVR $=\left[1, \mathrm{NVR}_{0}, \ldots, \mathrm{NVR}_{R}\right]$, where $\mathrm{NVR}_{j}=\sigma_{j}^{2} / \widehat{\sigma}^{2}$.

${ }^{6}$ See Bujosa et al. (2002) for a rigorous interpretation.

${ }^{7}$ Just for illustration in the case of several European IPI indexes, García-Ferrer and Bujosa-Brun (2000) compare trend derivatives obtained by using DHR and other standard signal extraction procedures: the basic structural model (BSM) of Harvey (1989) and the SEATS/TRAMO software (Gomez and Maravall, 1996). While the IRW was particularly useful for describing large and smooth changes in the trend, the other methods provide less smooth variations, and their associated trend derivatives are too volatile and irregular to be useful for dating turning points in monthly data.
} 
variance-covariance matrix $\Sigma_{a}$. The components of the vector of common factors, $\underline{f}_{t}$, are non-stationary, and we assume the usual conditions for the invertibility of the VARMA model (see Lütkepohl, 1993, p. 222).

Assume $\underline{y}_{t}$ is $I(d)$, and let $\boldsymbol{C}_{y}(k)$ be the generalized sample covariance matrices, that is:

$$
C_{y}(k)=\frac{1}{T^{2 d+d^{\prime}}} \sum_{t=k+1}^{T}\left(\underline{y}_{t-k}-\underline{\bar{y}}_{t}\right)\left(\underline{y}_{t-k}-\underline{\bar{y}}\right)^{\prime}
$$

where $\underline{\bar{y}}_{t}=\frac{1}{T} \sum_{t=1}^{T} \underline{y}$ and $d^{\prime}$ can be either 0 or 1 . Peña and Poncela (2006) show that for non-stationary factor identification these matrices play the same role as the sample covariance matrices in the stationary case. They show (Peña and Poncela, 2006, Theorem 1) that $\boldsymbol{C}_{y}(k)$ converges to a random matrix $\boldsymbol{\Gamma}_{y}$ that has $r_{1}$ eigenvalues greater than zero almost sure. Thus $r_{1}$ eigenvalues are a basis for the column space of the loading sub-matrix $\mathbf{P}_{\mathbf{1}}$ of the $r_{1}$ non-stationary factors.

Unfortunately we cannot assume that the sequence of vectors $\underline{\boldsymbol{e}}_{t}$ in (5) is normally distributed, or has zero mean and full diagonal covariance matrix $\Sigma_{e}$; therefore we cannot apply a formal statistical test for the number of common factors as in Peña and Poncela (2006). ${ }^{8}$ We can only inspect the eigenvalues and eigenvectors in order to find evidence of some large eigenvalues with stable eigenvectors for different values of $k$, and the remaining eigenvalues are relatively small with non-stable associated eigenvectors.

\section{TURNING-POINT CHARACTERIZATION OF THE SPANISH ECONOMY}

\section{Definitions}

We propose a set of definitions of recessions and expansions which, in our case, are directly linked to the IRW trend model outlined in the previous section. As noted earlier, the IRW trend model seems to have some advantages over other procedures regarding smoothness. Therefore, using the IRW trend derivative, our goal is simply to formalize and make transparent an alternative definition of turning points when using monthly seasonal data.

We first define the anticipation of a recession at time $t$ as the point where the trend derivative reaches its local maximum numerical value. We then define the confirmation of a recession as the point where the derivative becomes negative and remains so for at least 6 months. Analogously, we define the anticipation of an expansion at the local derivative's minimum, and the confirmation of an expansion when the derivative becomes positive and remains so for at least 9 months (García-Ferrer and Bujosa-Brun, 2000). The empirical time differences for an expansion and a recession are somehow heuristic and based on empirical observations over a large set of monthly economic series. Additionally, the turning-point characterization obtained following these rules must always agree with the information provided by annual growth rates of the reference variable. ${ }^{9}$

\section{Analysis of the historical recession data}

In Table I we provide information regarding 46 Spanish monthly economic indicators. Turning-point characterization has been obtained using the univariate LDHR model in Section 2 and the estimated individual IRW trends have been obtained from the original (seasonally unadjusted) monthly series. ${ }^{10}$ Cycles are obtained as the first difference (trend derivative) of the IRW trends and the different stages of the business cycle are characterized according to the definitions developed in Section 3.1. ${ }^{11}$ We have purposely excluded from the list any financial variables. Each panel in Table I shows information on the main economic indicators dealing with important contributions to the GDP growth over the years, as well as the dates regarding anticipation and confirmation of the 2008 recession. Panel (a) is devoted to gross fixed capital formation, mainly including variables related to the construction sector of the economy; panel (b) shows variables related to gross value added by industry-basically, industrial and electricity indicators; panel (c) presents features for the economic indicators related to the gross value added by the services sector, including mainly economic variables related to tourism, considered as one of the most important contributors to the Spanish GDP growth; panel (d) is devoted to the economic indicators related to private consumption; panel (e) shows the variables

\footnotetext{
${ }^{8}$ In fact, Poncela (2012) claims that the precise estimation of the number of common factors is still a cornerstone in both exact or strict as well as large and approximate dynamic factor models. In a less restrictive context, as in our case, the number of common factors is an open issue.

${ }^{9}$ The choice of statistical filter to extract the cyclical component is a crucial step in construction of a composite leading indicator. Commonly applied cycle estimation methods are phase-average trend (PAT), the Hodrick and Prescott (1997), and many band-pass filter methodologies like Baxter and King (1999) and Christiano and Fitzgerald (2003), among others. Using these filters to isolate the business cycle always requires a priori information either on the value of the smoothing parameter $\lambda$ or on the minimum and maximum duration of the business cycle. In our case, however, the use of LDHR does not impose any restriction on the estimated NVR parameters.

${ }^{10}$ Many applied time series involve forecasting seasonally adjusted series. However, as noted by Ghysels et al. (2006), pre-filtered data are predicted in the process of adjustment and the use of seasonally adjusted series may be problematic. See also Matas-Mir et al. (2008), who recommend using original data to avoid delays in the recognition of the end of a recession.

${ }^{11}$ For some alternatives see Harding and Pagan (2002) and Chauvet and Hamilton (2006).
} 
of the labour market; and finally panel (f) is devoted to the tax revenues. Each panel also shows the mean and the range periods for the anticipation and confirmation of the 2008 recession.

Following the information in Table I, we can derive the following conclusions. First, most variables in the table anticipate the recession before March 2008, with the exception of fuel and electricity consumption. Second, the means of the recession dates of variables pertaining to both gross fixed capital investment and private consumption sectors were September and June 2006, respectively. Other typically coincident and lagging sectors such as gross added value of industry and services or labour market statistics showed some delay and did not show clear

Table I. Turning-point characterization of the Spanish economy during the 2008 crisis

\begin{tabular}{|c|c|c|c|}
\hline Definition of variable & Sample & Anticipation of recession & Confirmation of recession \\
\hline \multicolumn{4}{|c|}{ (a) Gross fixed capital formation: consumption } \\
\hline Cement Consumption & $64.01-09.01$ & 06.01 & 07.01 \\
\hline Construction Production Index & $88.01-08.12$ & 04.09 & 06.10 \\
\hline Housing starts & $80.01-08.09$ & 03.04 & 06.05 \\
\hline Building permits & $92.01-08.12$ & 03.03 & 06.03 \\
\hline Total houses & $92.01-08.11$ & 05.09 & 06.06 \\
\hline Official licences & $89.01-08.11$ & 05.05 & 06.12 \\
\hline Official licences of buildings & $89.01-08.11$ & 05.05 & 06.12 \\
\hline \multirow[t]{3}{*}{ Official licences of civil buildings } & $89.01-08.11$ & 05.12 & 07.01 \\
\hline & Mean & 04.10 & 06.09 \\
\hline & Range & [03.03-06.01] & {$[06.03-07.01]$} \\
\hline \multicolumn{4}{|l|}{ (b) Gross value added by industry } \\
\hline Industrial Production Index & $75.01-08.12$ & 06.03 & 07.05 \\
\hline IPI manufacturing & $75.01-08.12$ & 06.03 & 07.05 \\
\hline Electricity consumption & $75.01-09.01$ & 06.09 & 08.06 \\
\hline IPI: consumption & $92.01-08.12$ & 06.05 & 07.04 \\
\hline IPI: durable goods & $92.01-08.12$ & 06.04 & 07.05 \\
\hline IPI: equipment goods & $92.01-08.12$ & 06.03 & 07.08 \\
\hline IPI: energy & $92.01-08.12$ & 06.02 & 07.03 \\
\hline Industrial new orders: general & $92.01-08.02$ & 05.12 & 07.11 \\
\hline Industrial new orders: consump. goods & $02.01-08.12$ & 05.12 & 07.11 \\
\hline Industrial new orders: intermed. goods & $02.01-08.12$ & 05.12 & 07.11 \\
\hline Stocks of industrial orders & $02.01-08.11$ & 06.01 & 07.07 \\
\hline \multirow{3}{*}{ Availability of equipment goods } & $00.01-08.11$ & 06.08 & 07.06 \\
\hline & Mean & 06.08 & 07.09 \\
\hline & Range & {$[05.12-06.09]$} & {$[07.03-08.06]$} \\
\hline \multicolumn{4}{|l|}{ (c) Gross value added by services } \\
\hline Air traffic & $70.01-09.01$ & 06.05 & 07.10 \\
\hline Passengers' entrance: tourists & $95.01-08.12$ & 07.04 & 07.10 \\
\hline Total tourists & $99.01-08.12$ & 06.04 & 07.10 \\
\hline Overnight accommodation & $99.01-08.12$ & 07.04 & 07.10 \\
\hline Transport of passengers by road & $85.01-08.12$ & 04.12 & 06.04 \\
\hline Indicator services activity & $02.01-08.12$ & 06.04 & 07.11 \\
\hline Fuel consumption & $78.01-08.11$ & 06.09 & 08.06 \\
\hline \multirow[t]{3}{*}{ Workers in SS system: services sector } & $85.01-09.01$ & 05.07 & - \\
\hline & Mean & 06.05 & 07.09 \\
\hline & Range & {$[04.12-07.04]$} & {$[06.04-08.06]$} \\
\hline \multicolumn{4}{|l|}{ (d) Private consumption } \\
\hline Consumption goods availability & $01.01-08.11$ & 06.04 & 07.06 \\
\hline Real wage indicator & $77.01-09.01$ & 06.01 & 07.11 \\
\hline Car registrations & $70.01-09.01$ & 06.02 & 06.06 \\
\hline Motorcycle registrations & $75.01-09.01$ & 04.09 & 07.02 \\
\hline Retailing sales indicator & $95.01-08.12$ & 06.06 & 08.02 \\
\hline Consumer confidence index & $86.06-09.01$ & 03.12 & 05.03 \\
\hline Home situation in the last 12 months & $86.06-09.01$ & 05.12 & 06.07 \\
\hline Home situation over next 12 months & $86.06-09.01$ & 03.12 & 05.01 \\
\hline Country situation in the last 12 months & $86.06-09.01$ & 03.12 & 04.10 \\
\hline Country situation over next 12 months & $86.06-09.01$ & 03.09 & 04.08 \\
\hline Commercial vehicles registration & $75.01-09.01$ & 04.11 & 06.09 \\
\hline \multirow[t]{3}{*}{ Wage income } & $77.01-09.01$ & 05.07 & 07.11 \\
\hline & Mean & 05.02 & 06.06 \\
\hline & Range & {$[03.12-06.04]$} & [04.01-08.02] \\
\hline
\end{tabular}


Table I. Continued.

\begin{tabular}{lccc}
\hline Definition of variable & Sample & Anticipation of recession & Confirmation of recession \\
\hline (e) Labour market: affiliations to SS system & & & 07.09 \\
Industry & $85.01-08.12$ & 06.12 & 07.03 \\
Construction & $85.01-08.12$ & 05.07 & 07.11 \\
Total & $82.01-09.01$ & 05.07 & 07.09 \\
Total system: industry & $95.01-08.12$ & 06.12 & 07.04 \\
Total system: construction & $95.01-08.12$ & 05.07 & 07.07 \\
& Mean & 06.02 & {$[07.03-07.11]$} \\
& Range & {$[05.07-06.12]$} & 06.11 \\
(f) VAT revenues & & & 06.11 \\
VAT revenues & & 05.05 & 05.05 \\
\end{tabular}

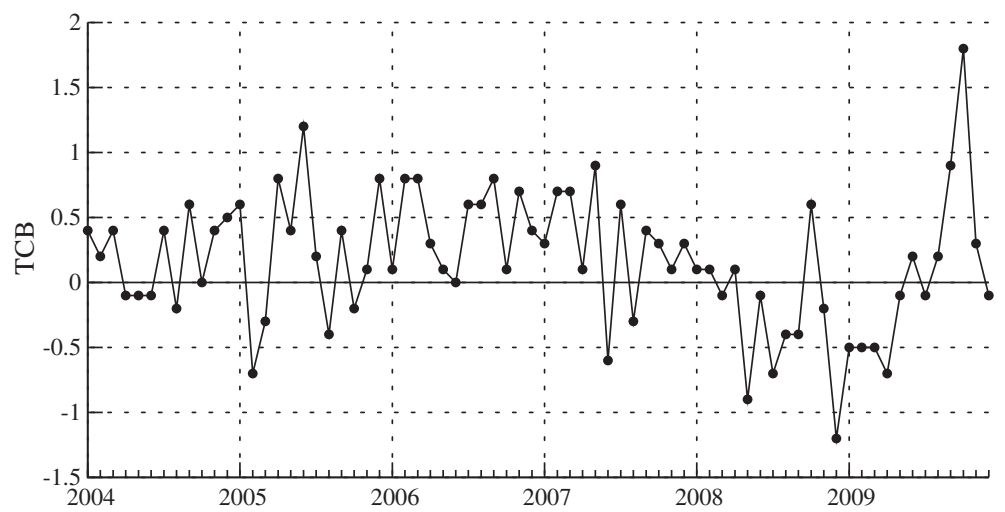

Figure 1. TCB leading indicator for Spain 2004:M1-2009:M12

recession signals until July 2007. Third, the range of the recession dates shows substantial variability, both within and across the different panels. This volatile behaviour of individual indicators makes the search for a CLI a sensible alternative.

\section{Building the composite leading indicator for the Spanish economy}

One of the key issues in building leading indicator models is the selection of the leading variables, and of their weighting scheme for their combination into a composite leading index. In this regard, The Conference Board (TCB) has been analysing US data for a very long time and have produced a short list of variables that they have combined into an overall index of leading indicators (CBILI). Such an index includes variables from the labour, housing and financial markets, as well as manufacturing order books and expectation variables. ${ }^{12}$ Recently, a similar set of variables (with the exception of the two indicators pertaining to the labour market) has been used by the TCB for the euro area, and a slightly different one for the Spanish leading index. ${ }^{13}$ Besides the issue of the effects of data vintages on model specification and forecast evaluation raised by Croushore and Stark (2003), the CBILIs have been subject to revisions and reweightings of the components over time, partly in response to perceived poor forecasting performance. Because of these revisions, the composite indexes and their monthly changes are no longer directly comparable with previous releases. Moreover, the only tool they use that would root out irrelevant indicators is to 'standardize' the variables. The standardization factors are inversely related to the standard deviation of the month-to-month changes in each component so all variables have the same degree of volatility. The more volatile components have lower standardization factors and less weight in the index. But, as Leamer (2009) points out, volatility is not the issue. The issue is predictability, and a low volatility indicator might be a terrible predictor.

In the case of Spain, Figure 1 shows the TCB leading indicator composite index from 2004 to 2009. Using this information to predict the forthcoming recession presents two problems. First, the TCB index does not show a clear

\footnotetext{
${ }^{12}$ Labour market (average weekly hours, manufacturing; Average weekly initial claims for unemployment insurance), Housing market (building permits, new private housing units), financial markets (interest rate spread, 10-year Treasury bonds less federal funds; stock prices, 500 common stocks; money supply, M2), manufacturing order books (manufacturers' new orders, consumer goods and materials; manufacturers' new orders, non-defence capital goods; vendor performance, slower deliveries diffusion index), man-on-the-street predictions (index of consumer expectations).

${ }^{13}$ In January 2009, the list of variables for the Spanish leading index was: money supply (M2), returns to long-term Spanish Treasury bonds, stock returns from the IBEX35 index, capital component of the industrial production index, and industrial new orders.
} 
Table II. Correlations between individual leading indicators and the CLI with the business cycle indicator

\begin{tabular}{lcr}
\hline Individual leading series and CLI & \multicolumn{2}{c}{ Sample period } \\
\cline { 2 - 3 } & 1978:M1-2009:M12 & 1980:M1-2009:M12 \\
\hline Cement comsumpt. & 0.86 & 0.88 \\
Car registrations & 0.67 & 0.68 \\
Commercial veh. registration & 0.82 & 0.85 \\
Housing starts & - & 0.87 \\
CLI & - & 0.88 \\
\hline
\end{tabular}

Table III. NVR estimates of individual monthly variables: estimation period 1986:M1-2009:M12

\begin{tabular}{lccccccc}
\hline Series & Trend & S12 & S6 & S4 & S3 & S2.4 & S2 \\
\hline Housing starts & 0.0062 & 0.0069 & 0.0025 & 0.0025 & 0.0064 & 0.0041 & 0.0034 \\
Cement consumption & 0.0039 & 0.0134 & 0.0029 & 0.0092 & 0.0266 & 0.0081 & 0.0009 \\
Car registrations & 0.0022 & 0.0185 & 0.0036 & 0.0060 & 0.0086 & 0.0066 & 0.0002 \\
Commercial vehicle reg. & 0.0034 & 0.0034 & 0.0048 & 0.0053 & 0.0127 & 0.0039 & 0.0007 \\
Industrial Prod. Index & 0.0015 & 0.0014 & 0.0023 & 0.0024 & 0.0053 & 0.0039 & 0.0012 \\
\hline
\end{tabular}

recession message until we are in the middle of it (May 2008). On the contrary, as we will show later, our CLI confirms the recession much earlier (October 2006). Second, in spite of the standardization procedure, the TCB index is extremely volatile. Its standard deviation $(0.52)$ is almost four times its mean $(0.16)$, so agents will have trouble in interpreting future directions of change.

In searching for targeted predictors (cycle drivers) for predicting US recessions, Leamer (2009) follows a different strategy. He splits GDP growth data into periods of normal growth and recession periods, and computes the contributions of different macroeconomic aggregates to GDP growth in percentage terms. The resulting recession and normal profiles are dramatically different. A recession has a big negative impact from inventories, while normal growth has virtually none. Similar results are observed for net exports, homes (residences) and durables. Although spending on residences makes a rather unimportant contribution to normal growth, it is the most important of the GDP components for predicting the highs and lows: the recessions and the recoveries. ${ }^{14}$ When analysing the long historical period since World War II until the present day, Leamer (2009) concludes that the US cycle is really a consumer cycle. The first expenditure component to turn down prior to recession is usually consumer spending on homes, then consumer durables, later business spending on equipment and, finally, the longest-lived business assets: factories and office buildings ... 'Not always, but eight times out of ten.'

In this paper, we have followed Leamer's approach by choosing four monthly indicators representing those aggregates that we consider to be the cycle drivers, namely: cement consumption (CC), car registrations (CR), housing starts (HS) and commercial vehicle registrations (CVR). ${ }^{15}$ The selected small number of leading series has been identified using both statistical criteria based on a dynamic correlation analysis and economic information taking expert knowledge into account. Prior to the selection process all series are filtered in the same way (using the LDHR model) to extract their cyclical component. A similar filter is also applied to our reference business cycle indicator (IPI), which serves as a benchmark for the leading indicator. As results in Table I show for the 2008 recession, the lead times between the reference business cycle indicator and the four leading variables are between 4 and 14 months. A more detailed information regarding lead times for the full sample 1978-2009 is provided in Section 4.1.2. Additionally, Table II shows the correlations of the individual leading indicators and the CLI with the IPI for different sample periods, since HS were not available before 1980:M1. All individual leading variables, as well as the CLI, show high correlations for both periods with the IPI for different samples.

Economically, the selected variables are also representative of different aspects of the Spanish economy since they belong to the main contributing sectors to GDP, namely private consumption, investment and construction. Considering indicators starting in 1980, we find that housing starts, referring to all residential buildings, are most promising in view of their long lead time of 14 months and high correlation of 0.87 . Similar variables like building permits are also part of the set of leading indicators used by the OECD, Conference Board and the ECB. ${ }^{16}$ Similar comments apply to cement consumption, which complements the information of housing starts regarding

\footnotetext{
${ }^{14}$ See also the pioneering contribution of Green (1997) regarding this issue. For the 2008 US recession, however, Hamilton (2009) sees the 2007-2008 oil shock as the indisputable contributing factor in explaining the collapse in automobile purchases and the slowdown in overall consumption spending.

${ }^{15}$ See Arouba et al. (2009) for a comparable 'small-data' dynamic factor model for the US real-time measurement of business conditions.

${ }^{16}$ In out case, however, the sample starting in 1992 is too short to cover all recession episodes.
} 
the construction sector. It also shows a high correlation of 0.88 an a lead of 4 months. Private consumption is the largest component of GDP, and consumer durables the component that first turns down prior to recession. Because its consumption can be postponed, car sales downturns always precede recessions. As the other leading variables in the CLI, it shows a long lead time of 11 months and a reasonably high correlation of 0.68 . Finally, commercial vehicle registration (representing the investment sector) is a good proxy of business spending on equipment that also has shown relevant leading information. For the whole sample it shows a high correlation of 0.85 and a long lead time of 8 months. For all variables we have used seasonally unadjusted data.

Empirical results regarding individual variables are shown in Table III. Our LDHR univariate algorithm identifies an IRW model for the trend and an RW model for the seasonal components. Table III includes estimates of the corresponding noise variance ratio (NVR) coefficients for the trend as well as for the main seasonal component and its harmonics. There are no large differences in the trend NVR estimates, although the four leading indicators show slightly less smooth trends than the IPI. Also the seasonal NVR estimates are quite similar for all series.
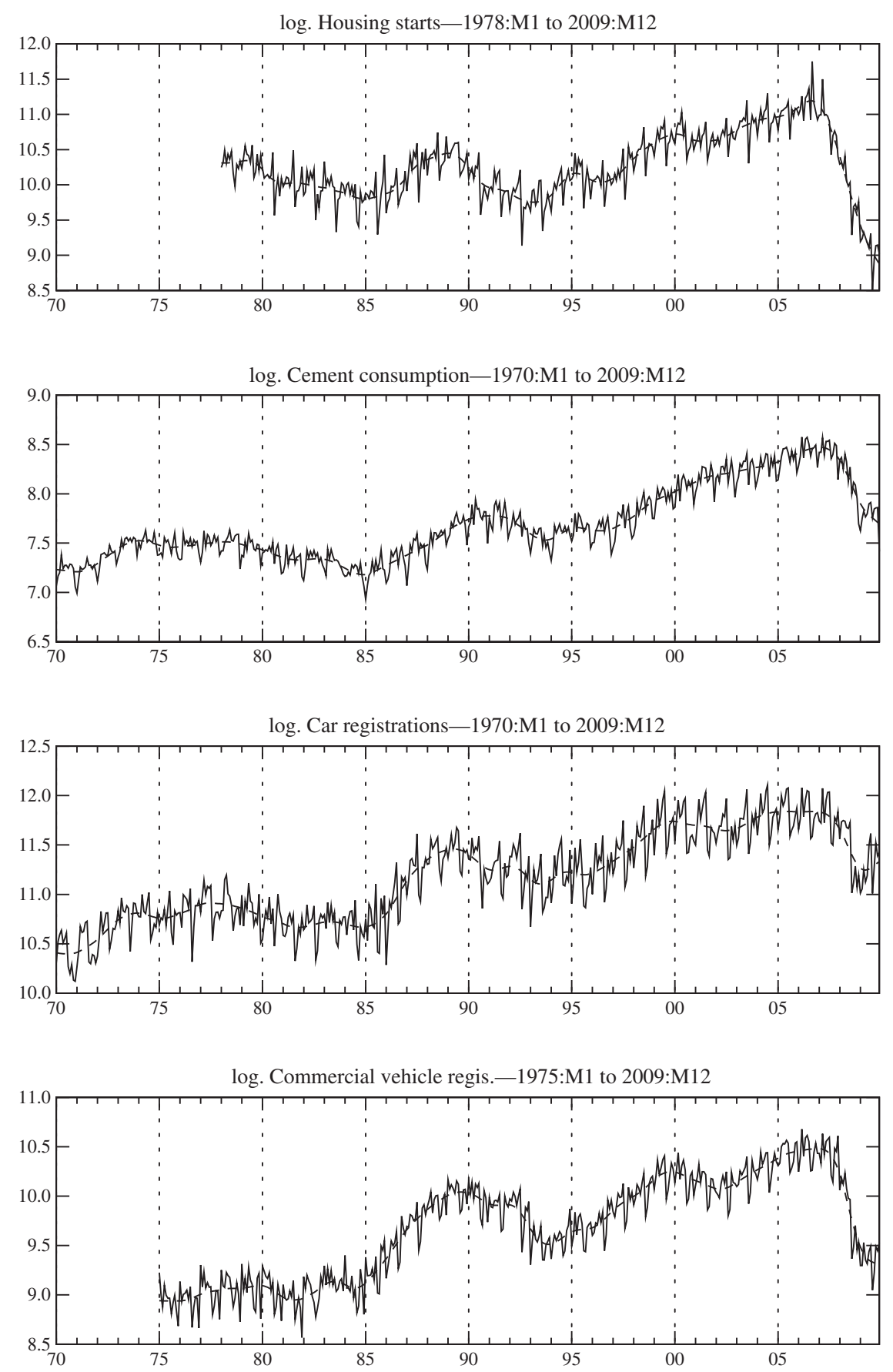

Figure 2. Monthly indicators in logs and their estimated IRW trends: housing starts, cement consumption, car registrations, and commercial vehicle registrations 
In Figure 2 we have plotted the leading indicators in logs and their smoothed IRW trends, where both nonstationarity in the mean and strong seasonality are evident. Using the trend estimates, we have obtained and plotted the estimated individual cycles (IRW trend derivatives) for the four monthly indicators (Figure 3).

In Figure 4 we show the four eigenvalues of the generalized sample covariance matrix of the four trends using the whole sample $\left[\mathbf{C}_{y}(k)\right.$ at the first five lags, $\left.k=1, \ldots, 5\right]$. As we can see, although the four eigenvalues are quite stable at different lags, the first one $\lambda_{1}$ is much larger than the others, indicative of the existence of only a single factor.

Figure 5 shows that the eigenvector corresponding to $\lambda_{1}$ is also quite stable at different lags $(k)$. In fact, it is more stable than the other eigenvectors, which are real at some lags, but two of them (not always the same pair) become complex conjugates for different values of $k$. Therefore, we will consider only one non-stationary common factor (since $\lambda_{1} / \sum \lambda_{i} \approx 90 \%$ of the variance). That common factor will be our CLI: a weighted sum of the four monthly indicators. The vector of weights is the eigenvector corresponding to the largest eigenvalue. In order to carry out the out-of-sample exercise we have computed the generalized sample covariance matrix $\mathbf{C}_{y}(5)$ using the iteratively estimated trends. Figure 6 shows the evolution of the components of the first eigenvector (the weights used to build the CLI) when the sample is updated.
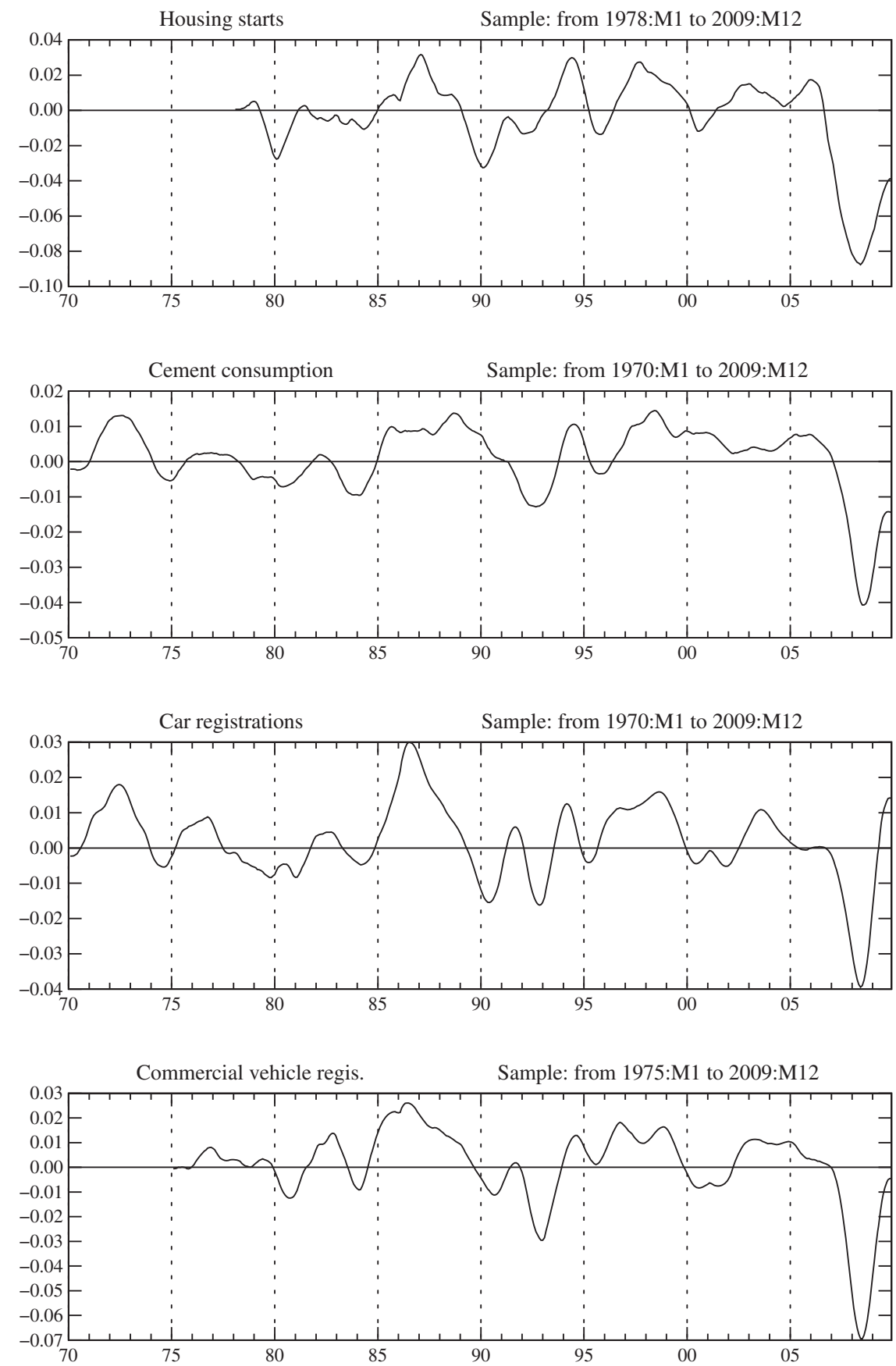

Figure 3. Estimated individual cycles (trend first differences) 


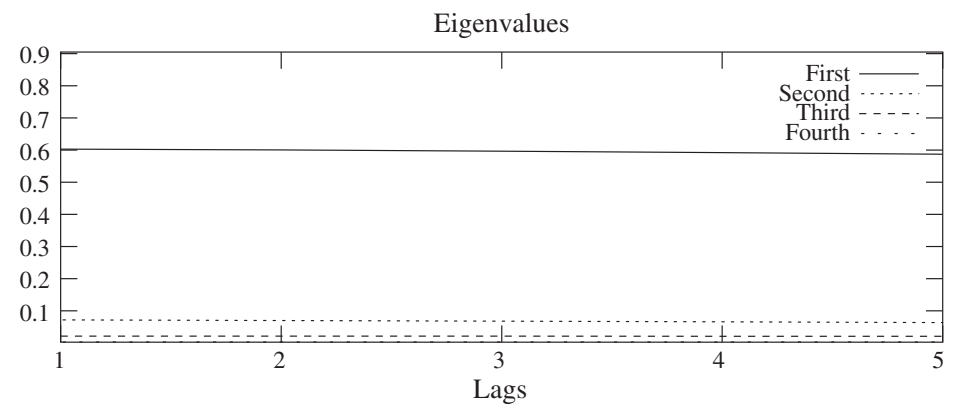

Figure 4. Eigenvalues of $\mathbf{C}_{y}(k)$ for different lags $k$

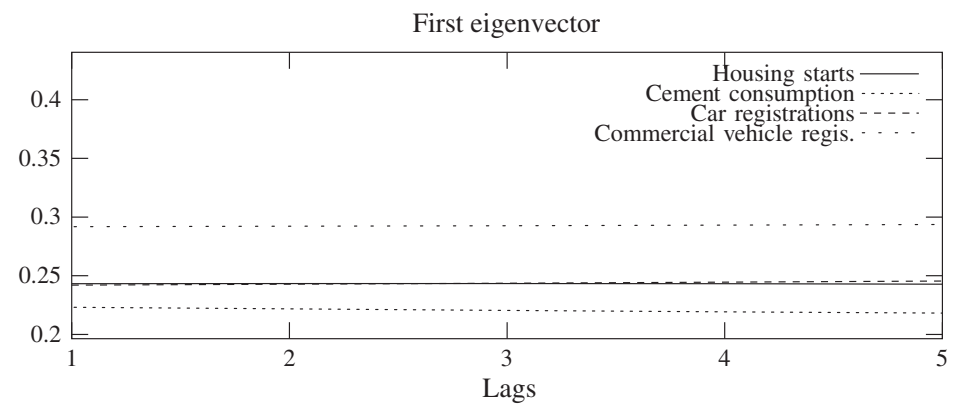

Figure 5. Normalized eigenvector associated with the larger eigenvalue of $\mathbf{C}_{y}(k)$ for different lags $k$

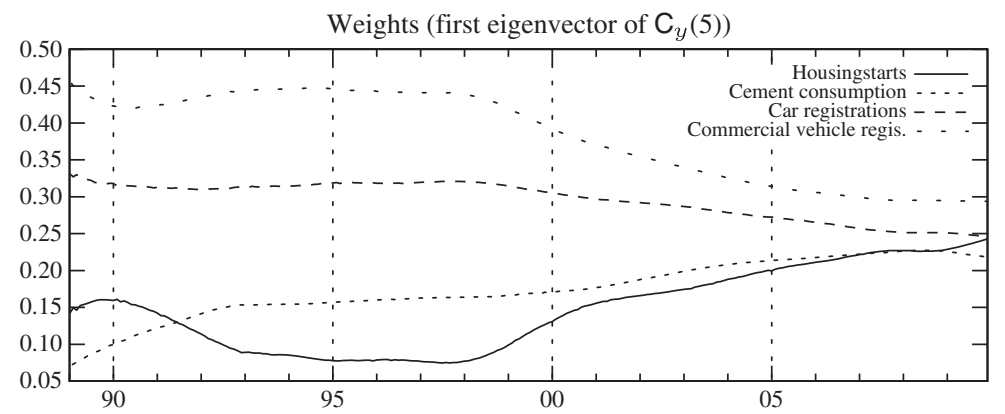

Figure 6. Evolution of the weights used to build the composite leading indicator (using only the information available at each point in time)

\section{EMPIRICAL RESULTS}

The starting point for the construction of leading indicators is the choice of variable that indicators are supposed to lead. In his seminal review of the literature, Marcellino (2006) concludes that we are still far from achieving a strong consensus on both the choice of target variable and on whether the classical or the deviation (growth) cycles could provide more useful information. Traditionally, GDP has been the main aggregate to look at. It could provide a reliable summary of the current economic conditions if it were available on a monthly basis. However, results both in the USA and in Europe are still too preliminary to rely on, so we have to look for other alternatives. ${ }^{17}$ In the past, the volume of sales, industrial production, real personal income, employment and unemployment series have been chosen on the basis of their time availability and minor revisions. Nevertheless, problems with partial coverage of the economy as well as a slightly delayed behaviour in some cases, particularly in the case of unemployment (Boldin, 1994), have precluded a general agreement and the choice of target is usually case dependent. Here, we shall be using the monthly IPI in spite of its partial coverage and the ever-increasing weight of the service sector in Spain. ${ }^{18}$ In our data, the IPI is promptly available and rarely revised. In this section, we will also analyse Spanish growth cycles

\footnotetext{
${ }^{17}$ The GDP is not the favourite economic aggregate of many analysts, including us. The reasons are well known: publication lag, quarterly and annual revisions with more complete information and benchmark or historic revisions take place every 5 years or so. As a result, there are many papers in the literature with radically different results, depending on the use of original or revised data. Besides, owing to its publication delay, it is not a very useful indicator to monitor the current state of the economy.

${ }^{18}$ A similar business cycle reference variable is used by de Bondt and Hahn (2010) in building a leading indicator for the Euro area.
} 


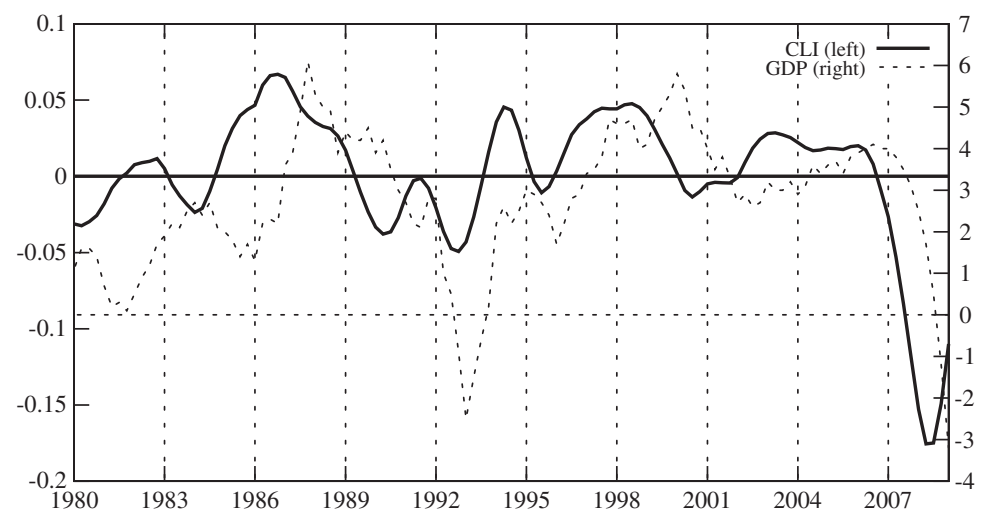

Figure 7. GDP and CLI growth cycles

Table IV. Turning point and recessions of CLI and annual GDP growth

\begin{tabular}{|c|c|c|c|c|c|}
\hline \multicolumn{3}{|c|}{ Troughs } & \multicolumn{3}{|c|}{ Peaks } \\
\hline CLI & GDP & \# quarters & CLI & GDP & \# quarters \\
\hline 1980:Q2 & 1981:Q2 & 4 & 1982:Q4 & 1984:Q1 & 5 \\
\hline 1984:Q2 & 1985:Q3 & 5 & 1986:Q4 & 1987:Q4 & 4 \\
\hline 1990:Q3 & 1991:Q3 & 4 & 1991:Q3 & 1991:Q4 & 1 \\
\hline 1992:Q4 & 1993:Q1 & 1 & 1994:Q3 & 1995:Q1 & 2 \\
\hline 1995:Q3 & 1996:Q1 & 2 & 1998:Q3 & 2000:Q1 & 6 \\
\hline 2000:Q3 & 2002:Q1 & 6 & 2006:Q1 & 2006:Q4 & 3 \\
\hline 2008:Q3 & 2009:Q2 & 3 & & & \\
\hline Mean & & 3.6 & & & 3.5 \\
\hline
\end{tabular}

and show how our CLI systematically precedes the peaks and troughs of the growth cycles during the whole sample period. In the first part of the section we will be showing the in-sample results, using the whole sample, while in the second part we will be showing some forecasting out-of-sample experiments. In the second part, the sample is always restricted to end at the beginning of the forecast period.

\section{In-sample results}

All results in this section (unless indicated otherwise) have been obtained using the whole sample period that ends in 2009:M12 or 2009:Q4.

Growth (deviation) cycles. In contrast to classical cycles, growth cycles represent alternating periods above and below trend rates of growth, and can be seen as short-term fluctuations around previous peaks and troughs. Questions related to the present stage of the business cycle, like whether or not there are signs of recovery, are directly linked to the concept of growth cycles. This type of fluctuation also has a long-standing history. Early work was done by Mintz (1969) and Klein and Moore (1985), among others, as well as reports on international economic indicators regularly published by international agencies. Most results show that the same indicators that proved reliable in monitoring classical cycles could serve as a useful tool for dating and monitoring growth cycles. Besides, growth cycles peaks lead their associated business cycles peaks and they occur more often. More recently, Niemira and Klein (1994) and García-Ferrer and Queralt (1998) show that, for the 1948-1990 quarterly US GDP data, growth cycles are also more symmetric in length and amplitude than business cycles. ${ }^{19}$ The techniques for constructing growth cycles from time series data are somewhat complicated given the need to rely on estimated unobserved trends. Many statistical institutes have been using variants of smooth annual rates (SAR) based on the combination of one low-pass and one band-pass filter that estimates the cycle as

$$
\mathrm{SAR}_{t}=\frac{\phi_{o}}{1-\phi_{1} B-\ldots-\phi_{5} B^{5}}\left(1-B^{4}\right) F^{4} \ln Y_{t}
$$

where $B$ and $F$ are the backward and forward operator and $Y_{t}$ is the economic aggregate. The low-pass filter is a Butterworth filter of order five, while the band-pass filter is the seasonal difference $\left(1-B^{4}\right)$ one. The biggest problem

\footnotetext{
${ }^{19}$ In spite of small differences among the components of the aggregate demand, García-Ferrer et al. (2001) show that for the period 1970 : Q1-1998:Q4 the Spanish growth cycles show a greater symmetry than their corresponding business cycles.
} 
(a)

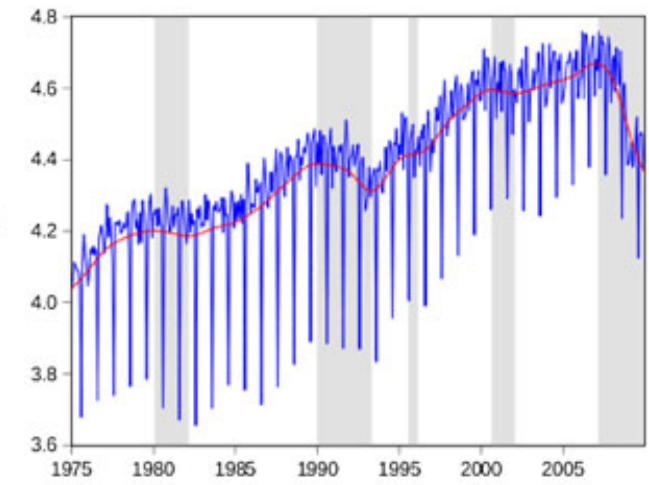

(b)

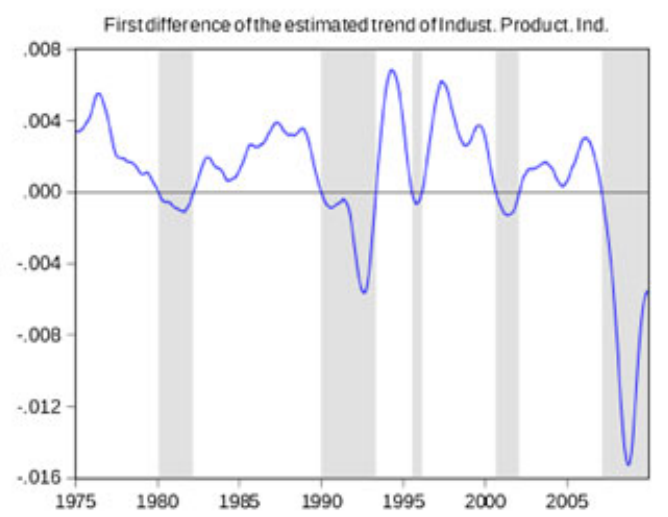

(c)

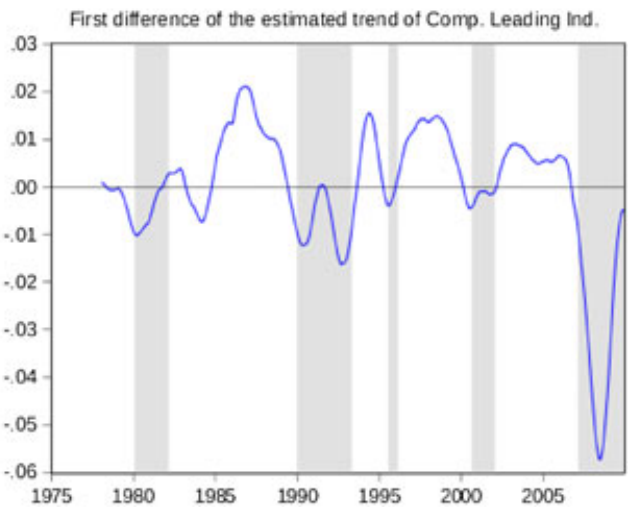

Figure 8. a) Industrial Production Index and its estimated IRW trend. (b) First difference of IPI's estimated trend. (c) Composite leading indicator. Shaded areas are the recession periods of IPI (negative values of its trend derivative)

using SAR is the loss of five data points (four at the beginning and one at the end) as a consequence of the centring operation that is needed for this indicator to be in phase with quarterly growth rates. Losing information at the end of the sample is critical in the neighbourhood of recession periods; therefore we have preferred to use the less smooth GDP annual growth rates. Following the usual approach of the Spanish Institute of Statistics, we have identified the turning points as the local maxima and minima. The duration of the expansion and contraction phases has to be equal to or greater than two quarters, and the minimum duration of a growth cycle is at least five quarters. On the other hand, transforming our monthly CLI indicator into quarterly observations has been achieved by simply using the last data point of the corresponding quarter. For the Spanish GDP case we have used quarterly seasonally adjusted data from 1978:Q1 to 2009:Q4.

In Figure 7, we have plotted together the GDP and the CLI growth cycles. It can be seen that the CLI always precedes the highs and lows of the GDP growth rates. Leading information is summarized in Table IV. The leading information in Table IV and in Figure 7 shows clearly the CLI anticipation of the peaks and troughs in annual GDP growth rates. The average anticipation is 3.5 quarters in peaks and 3.6 quarters in troughs. ${ }^{20}$ The leading period is reduced to only one quarter in the GDP peak in 1991:Q4 and in the 1993:Q1 trough. This fact may be seen as a contradiction if we pay attention to our definition of the duration of expansion and contraction phases. Both episodes

\footnotetext{
${ }^{20}$ Empirical results when using quarterly instead of annual growth rates is available from the authors upon request. The leading message remains unchanged, although both the individual and the mean lead lengths are slightly lower than those obtained in Table IV.
} 
Table V. Turning points and length of expansions and contractions of Spanish IPI, 1975:M1-2009:M12

\begin{tabular}{lcccccc}
\hline Begins & Recessions ends & Length & Begins & Expansions ends & Length & Ratio expan./rec. \\
\hline 1980:M2 & 1982:M3 & $25^{*}$ & 1982:M4 & $1989:$ M12 & 100 & 4 \\
1990:M1 & 1993:M4 & $40^{*}$ & 1993:M5 & 1995:M7 & 26 & 0.6 \\
1995:M8 & 1996:M2 & $6^{*}$ & 1996:M3 & 2000:M8 & 54 & 9 \\
2000:M9 & 2002:M1 & $16^{*}$ & $2003:$ M2 & $2007:$ M3 & 50 & 3.1 \\
2007:M3 & $?$ & $?$ & - & - & - & - \\
\hline
\end{tabular}

Table VI. Dates when recession begins for IPI and the individual and composite leading indicators

\begin{tabular}{|c|c|c|c|c|c|c|c|c|c|c|}
\hline \multirow{2}{*}{$\begin{array}{l}\text { IPI } \\
\text { Dates }\end{array}$} & \multicolumn{2}{|c|}{$\mathrm{CC}$} & \multicolumn{2}{|c|}{ CVR } & \multicolumn{2}{|c|}{ CR } & \multicolumn{2}{|c|}{ HS } & \multicolumn{2}{|c|}{ CLI } \\
\hline & Date & Lead & Date & Lead & Date & Lead & Date & Lead & Date & Lead \\
\hline 1980:M2 & 1978:M4 & 22 & 1980:M10 & 1 & 1977:M7 & 31 & 1979:M5 & 9 & 1979:M2 & 12 \\
\hline 1990:M2 & 1991:M3 & $?$ & 1989:M10 & 4 & 1989:M5 & 9 & 1989:M2 & 12 & 1989:M7 & 6 \\
\hline 1995:M8 & 1995:M5 & 3 & - & - & 1994:M1 & 10 & 1995:M4 & 4 & 1995:M4 & 4 \\
\hline 2000:M9 & - & - & 1999:M12 & 9 & 2000:M1 & 8 & 2000:M3 & 6 & 2000:M3 & 6 \\
\hline 2007:M3 & 2007:M2 & 1 & 2007:M1 & 2 & 2006:M10 & 5 & 2006:M9 & 6 & 2006:M10 & 5 \\
\hline
\end{tabular}

were caused, in a different way, by two special events that took place in Spain in 1992: the Olympic Games of Barcelona and the Universal Exposition of Seville (Expo'92). Whereas most developed economies were in recession by mid 1991, Spain was preparing for these events and the Spanish economy was not in a contraction phase. But when the rest of world was taking off from the recession, the Spanish economy came into a contraction. Thus the 1992 special events in Spain masked the recession. Looking at Figure 7, the big investments for the 1992 events caused a peak in the 1991:Q4 GDP growth rate. Without them, the Spanish economy would have remained in recession like the rest of the developed economies.

Other important facts to be mentioned from the results shown in Table IV are the six quarters lead of the 2001:Q1 GDP peak and the 2002:Q1 GDP trough. Although the Spanish economy was not officially in recession, the CLI foresees this business cycle. During the 2008 recession, for instance, the CLI anticipates in three quarters the negative annual GDP growth rate and the beginning of a potential expansion.

Classical IPI cycles. Spanish IPI (in logs) and its estimated IRW trend for the period 1975:M1-2009:M12 are shown in Figure 8(a), where both non-stationarity in the mean and strong seasonality are evident. NVR estimates for IPI are those shown in the last row of Table III. Using those estimates we have obtained and plotted the corresponding IPI cycle (trend derivative) in Figure 8(b). Shaded areas are recession periods according to the definitions stated in Section 3.1 and the complete turning point characterization is summarized in Table V. At this point, it is worth checking whether the length and timing of recessions (using monthly data) are in agreement with the results obtained by the annual growth rates (using annual data). The third column in Table V indicates the duration of contractions in months, and asterisks denote periods where estimated recessions agree with annual growth rates. In all cases, the definitions of expansions and recessions proposed earlier seem to work well, properly characterizing all the turning points in the data. When using annual data, the IPI shows three important recession periods: 1981-1982, 1990-1993 and 2007-2009 (which also appear when analysing GDP data); and two minor recessions (1996 and 2001) that do not translate into negative GDP growth rates.

To see how our monthly CLI leads IPI recessions over the last 35 years, we have plotted the CLI cycle and the corresponding shaded areas of IPI in Figure 8(c). With one exception (1983:M4), all remaining IPI recessions are clearly anticipated by the CLI. Table VI summarizes the beginning of the recession dates of the IPI and the individual composite leading indicators as well as the leading in months. Several comments are worth making. First, the leading information varies among different recessions and CC and CVR do not always anticipate all of them. ${ }^{21}$ Second, on the contrary, CR and HS correctly anticipate the beginning of all recessions, confirming similar results obtained by Leamer (2009) using US data. Third, the CLI also predicts historical recessions with leads ranging from 4 to 12 months.

\section{Out-of-sample (forecasting) results}

The evidence presented so far only proves one thing: from a historical point of view when using the whole sample, the CLI correctly anticipates the turning points of both GDP growth and IPI cycles. Although this result is encouraging,

\footnotetext{
${ }^{21}$ The surprising lagging result for cement in 1990:M2 is clearly caused by the episodes mentioned earlier regarding Expo'92 and the 1992 Olympic Games.
} 
Table VII. CLI leading IPI recessions

\begin{tabular}{llccc}
\hline Recession periods & $1990-1993$ & 1996 & 2001 & $2007-2009$ \\
\hline CLI & $1990:$ M2 & $1995: M 12$ & $2000:$ M9 & $2007:$ M5 \\
IPI & $1990:$ :11 & $1996:$ M & $2001: M 4$ & $2008:$ M8 \\
Lead (in months) & 9 & 3 & 7 & 10 \\
\hline
\end{tabular}

Table VIII. Estimated models for annual data. All estimated coefficients are statistically significant at 1\%. Sample: 1978-2006

\begin{tabular}{lccc}
\hline & Dependent variable: GDP growth rate & \\
\hline & CLI model & & ARIMA model \\
\hline$c$ & 0.022 & $c$ & 0.029 \\
CLI growth rate (-1) & 0.0008 & $\phi_{1}$ & 0.68 \\
CLI growth rate (-2) & 0.0002 & & 0.47 \\
CLI growth rate (-3) & 0.0006 & $R^{2}$ & 0.004 \\
$R^{2}$ & 0.82 & $\widehat{\sigma}$ & 28 \\
$\widehat{\sigma}$ & 0.006 & $T$ & 2 \\
$T$ & 25 & & \\
\hline
\end{tabular}

we should not forget that the trends to construct the CLI are smoothed estimates that, at each data point, use information pertaining to the whole sample. In terms of forecasting, however, the real test implies confirmation of the previous evidence when using only information available at the beginning of each forecast period. In this section, we will carry on two forecasting experiments. First, using the monthly CLI we will try to predict the last four IPI recessions. Starting in 1985:M1 we will iteratively update the CLI and IPI cycles using one observation at a time. Second, using the quarterly and annual CLIs we will evaluate its forecasting performance regarding the 2008 GDP recession. One- and four-step-ahead forecasts for the 2007-2009 period will be obtained and compared with alternative specifications.

Monthly IPI recessions. Working with real data in forecasting turning points implies the use of datasets that include the historical values that would actually be available to a forecaster at any point in time. As Croushore and Stark (2003) showed, this issue can be extremely important in practice since, in some cases, the empirical results are quite sensitive to the exact vintage of the data. At the same time, the use of real data in forecasting represents a trade-off between accuracy and timing. ${ }^{22}$ Therefore, the forecaster needs to make compromises between these two important goals. Trying to be conservative, we will postpone our CLI recession announcement date until its trend derivative becomes negative and remains so, for at least 6 months. The same rule applies in the case of IPI. Forecasting results are presented in Table VII. In all cases, estimation is performed iteratively using one observation at a time.

In the four IPI recession periods our CLI always predicts IPI's recession with a lead between 3 and 10 months. When comparing these results with those in Table VI we can observe some logical pattern recognition lags, as a consequence of the more conservative recession criteria used in this section. However, the leads in the four recession periods are very similar, independent of using real time or the whole sample period.

Annual and quarterly GDP forecasts. If we are interested in monitoring the current state of the economy, GDP should not be our target variable. However, it is so widely used that most public and private institutions want to translate any empirical economic analysis into GDP forecasts. In this regard, it is interesting to check whether the previous forecasting behaviour of our CLI can also be extended to GDP growth rate forecasts. To accomplish this goal we need to transform our monthly CLI into quarterly and annual observations. In the case of quarterly data, we have simply used the last data point of the corresponding quarter (March, June, September and December), while the annual growth rate has been computed directly as the difference between January and December each year in our monthly CLI.

In the case of annual data, empirical results from the linear dynamic econometric model using lagged values of the CLI annual growth rates between 1982 and 2006 are shown in Table VIII. This equation provides the GDP growth forecast for 2007. Adding the information corresponding to 2007, the equation is re-estimated to obtain the 2008

\footnotetext{
${ }^{22}$ No one in the profession questions the remarkable role that the NBER plays in identifying dates at which the US is experiencing an economic recession. These dates (based on a variety of economic indicators) are regarded as authoritative by both academic researchers and the public at large. However, since the NBER's Committee wants to be quite confident about its assessment before making a public declaration, its final statement reaches the general public with almost a 2-year delay. Thus the cost of this accuracy is that many members of the public continue to believe that the economy is in a recession long after a solid recovery is under way.
} 


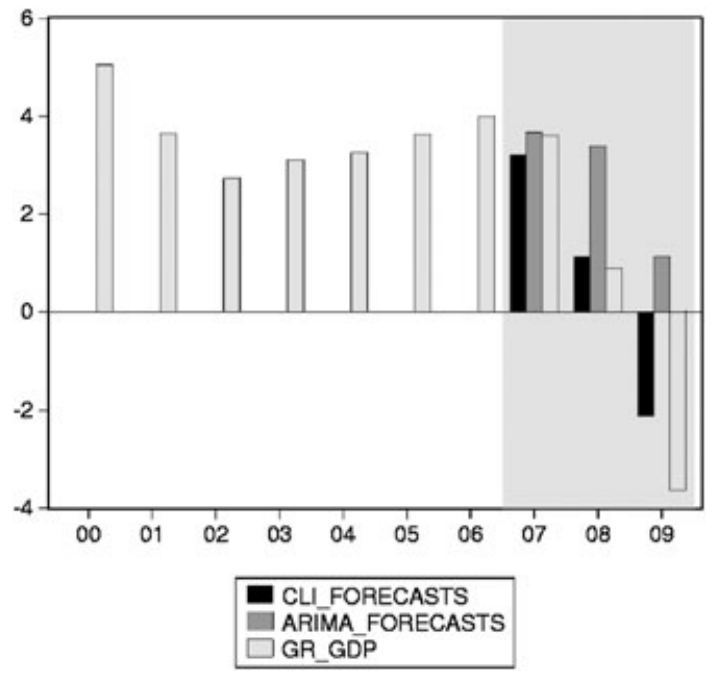

Figure 9. GDP growth and forecasts

Table IX. Estimated models for quarterly data. All the estimated coefficients are statistically significant at $1 \%$. Sample: 1978 : Q2-2006:Q4

\begin{tabular}{lcrr}
\hline & dependent variable: GDP growth rate & \\
\hline & CLI model & & ARIMA model \\
\hline$c$ & 0.85 & $c$ & 3.10 \\
CLI growth rate (-4) & 0.02 & $\phi_{1}$ & 1.29 \\
CLI growth rate (-8) & 0.03 & $\phi_{3}$ & -0.32 \\
GDP growth rate (-1) & 0.94 & $\Phi_{4}$ & -0.78 \\
GDP growth rate (-4) & -0.29 & & 0.92 \\
$R^{2}$ & & $R^{2}$ & 0.44 \\
$\widehat{\sigma}$ & 0.91 & $\widehat{\sigma}$ & 108 \\
$T$ & 0.49 & $T$ & \\
\hline
\end{tabular}

Table X. Quarterly GDP forecasts. Relative forecast RMSE ratios

\begin{tabular}{lcc}
\hline Year & ARIMA & CLI model \\
\hline 2007 & 1.00 & 0.714 \\
2008 & 1.00 & 0.859 \\
2009 & 1.00 & 0.564 \\
All & 1.00 & 0.811 \\
\hline
\end{tabular}

forecast, and so on. Note that the CLI data are also updated with each iteration. Thus we have three one-step-ahead forecasts corresponding to 2007, 2008 and 2009. The forecasts of the alternative ARIMA benchmark models are similarly obtained. Observed GDP growth values and alternative forecasts are plotted in Figure 9. While the values of both forecasts are roughly similar and close to the observed growth values in 2007 (still a normal growth year), our dynamic CLI model provides much better forecasts for the 2008-2009 period. ${ }^{23}$

In the case of quarterly data, our dynamic econometric model includes lagged values of both GDP and CLI growth rates. Initial estimation results from 1982:Q1 to 2006:Q4 are shown in Table IX. Forecasts for 2007:Q1 are obtained directly from this equation. Adding one observation at a time, the equation is re-estimated to obtain the 2007:Q2 forecasts, and so on. The forecasts of the benchmark ARIMA models are similarly obtained. Forecast comparisons are then based on 12 one-step-ahead results. In Table X we have included the relative RMSE ratios of both models during the 2007-2009 forecasting period. In the three individual years, as well as in the whole period (all) the forecasting gain of the CLI model is substantial, particularly in 2009 with a reduction of $43 \%$ in the RMSE.

\footnotetext{
${ }^{23}$ At the end of 2007 the GDP growth forecasts of the Spanish Ministry of Finance for 2008 was 3.3\%, while the panel of consensus forecasts was a $3.0 \%$ growth, roughly similar to those obtained by the benchmark growth ARIMA model (see http://www.la-moncloa.es/ Programas/OEP).
} 


\section{CONCLUSIONS}

This paper reports on the construction of a new composite leading indicator for the Spanish economy in order to forecast recessions. One novelty of our approach is that such an indicator is based on the low-frequency components of non-stationary monthly economic variables rather than on the stationary transformation of seasonally adjusted series. This approach guarantees that the resulting indicator is reasonably smooth, avoiding the typical volatility shown in many leading indicators available in the literature. Such volatility may be confusing for economic agents in interpreting future directions of change. On the other hand, using only the low-frequency components facilitates the search for the number of common factors in the dynamic factor model identification. Information from the individual economic variables, on which the indicator is based, showed that signals of the 2008 recession were evident in the Spanish economy before the bursting of the financial bubble in August 2007. This announcement was generalized across most economic sectors. Our composite leading indicator based upon a reduced number of targeted variables conveys a similar message regarding recession announcement.

The usefulness of the new indicator has been checked through both historical (in-sample) behaviour and outof-sample forecasting performance. When using the whole sample our composite leading indicator systematically precedes the peaks and troughs of both the GDP growth cycles as well as the industrial production classical cycles, with leads that change among different historical periods. On the other hand, the use of our composite leading indicator provides significant aid in forecasting annual and quarterly GDP growth rates during the 2008 recession. Using only real data available at the beginning of each forecast period, our leading indicator one-step forecasts shows sizable improvements over other benchmark alternatives, including panels of consensus forecasts.

One of the problems in constructing leading indicator models is that certain categories such as leading, coincidental and lagging are not permanent through time; neither are the same across different countries. In the case of output growth, for instance, recessions in the USA and other countries might not appear to have had common causes, in the sense that different indicators have worked well for some recessions but not others. However, when splitting GDP growth data into periods of normal growth and recessions and computing the contributions of different macroeconomic aggregates to GDP growth, the resulting recession and normal profiles are dramatically different. The search for these cycle drivers together with the use of statistical techniques aiming to obtain targeted predictors seems to be an adequate approach in reducing forecast errors and a promising venue for future research.

\section{ACKNOWLEDGEMENTS}

We are very thankful to two anonymous referees who were extremely helpful in revising previous versions of this paper. The preparation of this paper and the research that it describes have been supported by the Spanish MEC project ECO2009-10287.

\section{REFERENCES}

Arouba SB, Diebold FX, Scotti C. 2009. Real-time measurement of business conditions. Journal of Business and Economic Statistics 27: 417-427.

Bai J, Ng S. 2008. Determining the number of factors in approximate factor models. Journal of Econometrics 146: $304-317$.

Baxter M, King RG. 1999. Measuring business cycles: approximate band-pass filters for economic time series. Review of Economics and Statistics 81: 575-593.

Boivin J, Ng S. 2006. Are more data always better for factor analysis Journal of Econometrics 132: $169-194$.

Boldin M. 1994. Dating turning points in the business cycle. Journal of Business 67: 97-131.

Bujosa A, Bujosa M, García-Ferrer A. 2002. A note on the pseudo-spectra and the pseudo-covariance generating functions of ARMA processes. Documentos del Instituto Complutense de Análisis Económico 0203, Universidad Complutense de Madrid.

Bujosa M, García-Ferrer A, Young PC. 2007. Linear dynamic harmonic regression. Computational Statistics and Data Analysis 52: 999-1024.

Chauvet M, Hamilton J. 2006. Dating business cycle turning points. In Nonlinear Time Series Analysis of Business Cycle, Milas C, Rothman P, van Dijk D (eds). Elsevier: Amsterdam; 1-54.

Chauvet M, Piger J. 2005. The real-time performance of business cycle dating methods. Working paper, University of California, Riverside, CA.

Christiano L, Fitzgerald T. 2003. The band pass filter. International Economic Review 44: 435-465.

Chun H, Kekes S. 2010. Sparse partial least squares regression for simultaneous dimension reduction and variable selection. Journal of the Royal Statistical Society B 72: 3-25.

Clements M, Galvao A. 2008. Macroeconomic forecasting with mixed-frequency data: forecasting output growth in the United States. Journal of Business and Economic Statistics 26: 546-554.

Clements M, Galvao A. 2009. Forecasting US output growth using leading indicators: an appraisal using MIDAS models. Journal of Applied Econometrics 24: 1187-1206.

Croushore D, Stark T. 2003. A real-time data set for macroeconomists: does the data vintage matter? Review of Economics and Statistics 85: 605-617. 
de Bondt G, Hahn E. 2010. Predicting recessions and recoveries in real time: the euro area wide leading indicator (ALI). Working paper 1246, European Central Bank.

de Mol C, Giannone D, Reichlin L. 2008. Forecasting using a large number of predictors: is Bayesian regression a valid alternative to principal components? Journal of Econometrics 146: 318-328.

Diebold F, Rudebusch G. 1996. Measuring business cycle: a modern perspective. Review of Economics and Statistics 78: 67-77.

Efron B, Hastie T, Johnstone I, Tibshirani R. 2004. Least angle regression. Annals of Statistics 32: 407-499.

Eickmeier S, Ng T. 2011. Forecasting national activity using lots of international predictors. International Journal of Forecasting 27: 496-511.

García-Ferrer A, Bujosa-Brun M. 2000. Forecasting OECD industrial turning points using unobserved components models with business survey data. International Journal of Forecasting 16: 207-227.

García-Ferrer A, Poncela P. 2002. Forecasting international GDP growth rates through common factors and other procedures. Journal of Forecasting 21: 225-244.

García-Ferrer A, Queralt R. 1998. Using long-, medium-, and short-term trends to forecast turning points in the business cycle: some international evidence. Studies in Nonlinear Dynamics and Econometrics 3: 79-105.

García-Ferrer A, Queralt R, Blazquez C. 2001. A growth cycle characterisation and forecasting of the Spanish economy: $1970-1998$. International Journal of Forecasting 17: 517-532.

Ghysels E, Osborn D, Rodrigues P. 2006. Leading indicators. In Handbook of Forecasting, Elliot G, Granger C, Timmerman A (eds). Elsevier: Amsterdam; 659-711.

Ghysels E, Sinko A, Valkanov R. 2007. MIDAS regressions: further results and new directions. Econometric Reviews 26: 53-90.

Gomez V, Maravall A. 1996. Programs TRAMO and SEATS , instructions for the user (BETA Version: Sept. 1996). Working paper 9628, Bank of Spain, Madrid.

Green R. 1997. Follow the leader: how changes in residential and non-residential investment predict changes in GDP. Real Estate Economics 25: 253-270.

Hamilton J. 1989. A new approach to economic analysis of nonstationary time series and the business cycle. Econometrica 57: $357-384$.

Hamilton J. 2009. Causes and consequences of the oil shock of 2007-2008. Working paper, University of California, San Diego, CA.

Harding D, Pagan A. 2002. Dissecting the cycle: a methodological investigation. Journal of Monetary Economics 49: 365-381.

Harvey AC. 1989. Forecasting Structural Time Series Models and the Kalman Filter (1st edn). Cambridge University Press: Cambridge, UK.

Hodrick RJ, Prescott EC. 1997. Postwar U.U. business cycles: an empirical investigation. Journal of Money, Credit and Banking 29: $1-16$.

Kim C, Nelson C. 1998. Business cycle turning points: a new coincident index and tests of duration dependence based on a dynamic factor model with regime-switching. Review of Economics and Statistics 80: 188-201.

Kitagawa G. 1981. A nonstationary time series model and its fitting by a recursive filter. Journal of Time Series Analysis 2: $103-116$.

Klein P, Moore GH. 1985. Monitoring Growth Cycles in Market-Oriented Countries: Developing and Using International Economic Indicators. Ballinger: Cambridge, MA.

Leamer EE. 2009. Macroeconomic Patterns and Stories. Springer: Berlin.

Lütkepohl H. 1993. Introduction to Multiple Time Series Analysis (2nd edn). Springer: Heidelberg.

Lütkepohl H. 2006. Forecasting with VARMA models. In Handbook of Forecasting, Elliot G, Granger C, Timmerman A (eds). Elsevier: Amsterdam; 287-326.

Marcellino M. 2006. Leading indicators. In Handbook of Forecasting, Elliot G, Granger C, Timmerman A (eds). Elsevier: Amsterdam; 879-960.

Matas-Mir A, Osborn DR, Lombardi MJ. 2008. The effect of a seasonal adjustment on the properties of business cycle regimes. Journal of Applied Econometrics 23: 257-278.

Mintz I. 1969. Dating post-war business cycles, methods and their application to Western Germany, 1950-1967. Occasional paper 107, NBER, New York.

Niemira M, Klein P. 1994. Forecasting Financial and Economic Cycles. Wiley: New York.

Peña D, Poncela P. 2004. Forecasting with nonstationary dynamic factor models. Journal of Econometrics 119: 291-321.

Peña D, Poncela P. 2006. Nonstationary dynamic factor analysis. Journal of Statistical Planning and Inference 136: $1237-1257$.

Poncela P. 2012. Further research on conditionally heteroskedastic factor models. International Journal of Forecasting 28: 94-96.

Poncela P, García-Ferrer A. 2010. The Effects of Disaggregation on Forecasting Nonstationary Time Series. Universidad Autónoma de Madrid.

Stock J, Watson M. 2002. Macroeconomic forecasting using diffusion indexes. Journal of Business \& Economic Statistics 20(2): 147-162.

Stock J, Watson M. 2003. How leading indicator forecasts perform during the 2001 recession? Economic Quarterly 89: 71-90.

West M, Harrison J. 1997. Bayesian Forecasting and Dynamic Linear Models (2nd edn). Springer: New York.

Young PC, Pedregal D, Tych W. 1999. Dynamic harmonic regression. Journal of Forecasting 18: 369-394.

Authors' biographies:

Marcos Bujosa-Brun is an associate professor at the Universidad Complutense de Madrid. He obtained his PhD in Economics at the Universidad Autonóma de Madrid in 2001. His research interests include modelling in the frequency domain and forecasting seasonal economic time series. On these topics, he has published in the International Journal of Forecasting and Computational Statistics and Data Analysis.

Antonio García-Ferrer (PhD from U.C. Berkeley, 1978) is a professor of Econometrics in the Departamento de Análisis Económico: Economía Cuantitativa at Universidad Autónoma de Madrid where he has been since 1980. He is an assistant professor at the Universidad de Alcalá de Henares (1978-1980) and a fulbright visiting professor at the Booth GSB of the University of Chicago in 1984-1985. He is an associate editor of the International Journal of Forecasting and President of the International Institute of 
Forecasters (2008-2012). His research interests include modeling and forecasting seasonal time series, turning point predictions, and leading indicators. He has published several books and more than 60 papers in the Journal of Development Economics, Journal of Business and Economic Statistics, Journal of Economic Studies, Journal of Forecasting, International Journal of Forecasting, Health Economics, Journal of Transport Economics and Policy, Computational Statistics \& Data Analysis, Stochastic Environmental Research and Risk Assessment, Studies in Nonlinear Dynamics, and Econometrics and Accident Analysis and Prevention.

Aránzazu de Juan Fernández is an associate professor at the Universidad Autónoma de Madrid. He obtained his PhD in Economics at Universidad Autónoma de Madrid in 1992. His research interests are time series analysis, combinations of forecasts, and economic growth and business cycles. She has published on these topics in the International Journal of Forecasting, Empirical Economics, Health Economics, and Accident Analysis and Prevention, among others.

Authors' addresses:

Marcos Bujosa, Departamento de Fundamentos del Análisis Económico II, Universidad Complutense de Madrid, Somosaguas, 28223 Madrid, Spain.

Antonio García-Ferrer, Departamento de Análisis Económico: Economía cuantitativa, Universidad Autónoma de Madrid, 28049 Madrid, Spain.

Aránzazu de Juan, Departamento de Análisis Económico: Economía cuantitativa, Universidad Autónoma de Madrid, 28049 Madrid, Spain. 